\title{
O inferno do clássico ou Uma conta de soma zero
}

\section{The classic's hell or An account which adds to zero}

https://doi.org/10.34112/2317-0972a2016v34n68p139-152

\section{Roberto Goto ${ }^{1}$}

RESUMO: O presente texto é um ensaio sobre a crise do clássico. Ele a mapeia procurando definir os contornos dos círculos que circunscrevem o entorno adverso à leitura dos clássicos, ou seja, que delineiam seu inferno.

Palavras-chave: Filosofia; literatura; clássicos; leitura.

ABStRACt: This essay addresses the crisis of the classic piece of literature. It cartographs the crisis by seeking to define the outlines of the circles that circumscribe the adverse boundaries of reading the classics, that is, a map of its hell.

KEYWORDS: Philosophy; literature; classics; reading.

"Um clássico é um clássico, e vice-versa”. A frase, vazada assim mesmo, em itálico, e assinada por “OS EDITORES”, encima o curto texto de abertura de uma edição especial de dois ensaios de Ítalo Calvino, com primazia para "Por que ler os clássicos", que dá título ao pequeno livro. A tautologia, no caso, é uma evidência que aponta para o avesso de sua significação - uma evidência de que, na contemporaneidade, $o$ clássico não se basta nem se sustenta por si mesmo, não se identifica nem se define

1. Universidade Estadual de Campinas, Campinas, SP, Brasil. 
por sua mera presença. Por que falar da importância e do valor ${ }^{2}$ de ler os clássicos, a não ser porque não se tem mais presente, de forma autossuficiente e autoevidente, tal importância?

Talvez esse seja um desses truísmos que passam despercebidos, mas não deixam por isso de ser perfeitamente óbvios, pois é fácil notar que ninguém se sente impelido ou obrigado a ler a obra de um autor porque ele é classificado como clássico. É exatamente o que ocorre no espaço tido por excelência - e eleição - para o cultivo dos clássicos: a escola. "Por que devo ler José de Alencar e Machado de Assis?”, o aluno pergunta. Responder-lhe "porque são clássicos da Literatura Brasileira” não o convence, é o mesmo que nada dizer. “E daí?”, ele replica.

Não é exagero dizer que o ácido ambiente que o clássico respira é o de terra arrasada, e que o cenário do drama ou da tragicomédia representada pela leitura dos clássicos lembra estes versos do poema "Beethoven”, de Carlos Drummond de Andrade:

Meu caro Luís, que vens fazer nesta hora

de antimúsica pelo mundo afora? (ANDRADE, 1978, p. 82).

Talvez o entorno não seja propriamente de antimúsica, mas, antes, de não música, uma atmosfera esvaziada da arte das musas: se o clássico ainda invoca a musa e se investe como seu porta-voz, o que ele encontra hoje ao redor é um ar do qual as musas se ausentaram, expulsas pelos ídolos da massa, os quais ou não têm musas ou se consideram superiores a elas, ao ponto justamente de se exibirem como seus substitutos e exterminadores - e é então sem a companhia dum Orfeu ou dum Virgílio que calha de se empreender a descida pelos caminhos tortuosos e pedregosos que compõem os círculos do inferno do clássico.

\section{Primeiro círculo}

O círculo mais amplo ou extenso, que contém os demais, é o da cultura do entretenimento de massa. Cabe falar, em seu caso, que o obstáculo que ele antepõe à leitura dos clássicos é da ordem da atitude, incidindo de forma direta e letal sobre

2. Calvino (2009, p. 30) conclui o citado ensaio afirmando que "deveria reescrevê-lo ainda uma vez para que não se pense que os clássicos devem ser lidos porque 'servem' para qualquer coisa. A única razão que se pode apresentar é que ler os clássicos é melhor do que não ler os clássicos.” 
o ler. Talvez nada seja tão contrário e nocivo à leitura propriamente dita que a decodificação que se faz passar por aquela, disseminando-se como hábito e gosto, decodificação que consiste na conversão quase automática dos signos em imagens e sensações mais ou menos estereotipadas, que todos são capazes de sentir e reproduzir, e - praticada e vivida como consumo - é quase sempre complementada por ações e sentimentos de participação, de pertencimento à massa: "lê-se", isto é, curte-se algo porque todo o mundo o está curtindo (não por acaso é um bestseller). Curtir significa mesmo, efetivamente, encurtar e abreviar o caminho da leitura, não alongar nem se desviar e se perder em cismas interpretativas: em suma, chegar logo ao fim da trama, ao desfecho do enredo. Por isso: "Li de uma só sentada"; "Não consegui parar de ler”... A avaliação é quantitativa, o prazer está ligado à quantidade de emoções que a decodificação fez o decodificador viver; daí ele vai partir para outro livro da série e/ou do mesmo autor, produzido nos mesmos moldes, com promessas de sensações e emoções semelhantes, dos quais o decodificador tomará novas doses.

Em que consiste, por sua vez, uma leitura que, na falta de melhor palavra, podemos chamar de artística, ou seja, que leve na devida consideração a arte do escritor? Não é justamente essa a leitura de que se faz merecedor um clássico, na justa medida em que, se ele se tornou clássico, o foi por conta de sua arte, a arte da palavra? Tratase de uma leitura que frequentemente se interrompe, que faz pausas - algumas vezes para o leitor meditar e ponderar sobre o que acaba de ler, outras para aprofundar a assimilação ou refinar a degustação das palavras, imagens e ideias, outras ainda para dialogar com personagens. Em tal caso, chegar ao fim da trama é bastante ou absolutamente secundário; importa mais enredar-se nas relações, demorar-se na apreciação da contextura, dos elementos e efeitos da arte literária tal como praticada e realizada pelo autor. Daí é que pode advir - e advém efetivamente - a fruição da leitura como prazer propriamente estético, o qual ocupa o extremo oposto ao da curtição embutida naquela decodificação, na medida em que só emerge a partir de um trabalho de desvendamento de signos que não se abrem automaticamente, não revelam seus segredos imediatamente à primeira visada.

Ademais, essa leitura supõe e implica a autonomia do leitor nesse sentido mais essencial de constituir-se como subjetividade livre ante outra subjetividade livre. É aí - apelemos para a expressão popular - que "a porca torce o rabo", pois essa autonomia não é só trabalhosa como exige uma certa audácia, talvez mais forte que a preconizada por Kant. Não se trata apenas de ousar saber, mas de ousar ser - ousar ser o que se é para dialogar com um outro, alguém que é diferente do que se é. É 
como se o texto apelasse ao leitor nesses termos: vem, interpreta-me, decifra-me; não sejas uma maria-vai-com-as-outras; não tenhas medo de encontrares em mim o que ninguém mais encontrou, e de não achares o que todo o mundo diz ter achado - ousa ser tu mesmo...

Não é raro professores toparem com a seguinte situação: o aluno demanda e reclama autonomia na interpretação de textos; revolta-se quando alguém dá mostra de querer impor pontos de vista, na medida em que pretende que sua interpretação valha o mesmo que outras; contudo, não raramente, ele abre mão de sua interpretação, trocando-a por interpretações já prontas, que ele copia ou reproduz e apresenta como se fossem suas. Esse é o caso dos manjados resuminhos de obras literárias que o vestibulando "lê", imaginando que com isso conheceu as obras - não fazendo mais, evidente e efetivamente, que tomar contato com uma das interpretações possíveis delas -, e dos famigerados "trabalhos" acadêmicos sugados da internet, como outrora eram recortados, por vezes literalmente, das enciclopédias impressas. Ficam patentes nesses casos não só a comodidade e a malandragem, mas essa ausência absoluta da ousadia de ser, a contraditória abdicação da autonomia que é tão reclamada pelo indivíduo quando é de seu interesse - contraditória, é lógico, porque justamente quando se requer do sujeito que ele ande e corra com as próprias pernas, ele foge da raia e vai buscar e pegar para si muletas, andadores, cadeiras de rodas, embora disponha do movimento das pernas.

Essencial na leitura dos clássicos, essa autonomia é que possibilita ao leitor aproximar-se de sua riqueza e explorar sua fonte: o caráter multifacetado, proteiforme dessas obras. Por ela se percebe que um clássico, longe de ser um fóssil cristalizado pela tradição, revive a cada leitura, ganhando novas cores, novos aspectos, inclusive à custa de críticas. Essas só conseguem qualificá-lo - justamente como algo vivo. No entanto, o que ocorre quando se tenta enfiar um clássico numa decodificação como as que se praticam com os produtos da cultura de massa, o que se tem é desqualificação e morte. $\mathrm{O}$ imperativo é o da curtição, não se cogitando, em momento algum, do direito da obra de desafiar o "curtidor", o consumidor. Pelo contrário, é ele que a desafia: "divirta-me”. Mas ela não o diverte, não o entretém; portanto, é chata...

\section{SEgundo CÍRCULO}

O segundo círculo do inferno do clássico chama-se Politicamente Correto e tem duas faces, uma censória e outra purista. Comecemos pela segunda: herdeira, por 
um lado (o esquerdo), das patrulhas ideológicas, projeta sobre autores e obras a sombra da sentença restritiva - "isso é burguês" ... Implícita nessa restrição dorme a ideia de que o conteúdo da obra contamina o leitor, pondo-o em risco de contrair uma doença - a do "burguesismo" -, como julgavam e propagavam os militantes da "Revolução Cultural" chinesa, capitaneada pelo chamado "Bando dos Quatro" com o beneplácito do "timoneiro-mor" Mao Zedong, e cujas repercussões no campo artístico podem ser aquilatadas no filme Balzac e a costureirinha chinesa, dirigido por Dai Sijie. Por outro lado (o direito), o purismo do Politicamente Correto não deixa de lembrar a política cultural dos nazistas, que proibiram os judeus de frequentar as audições públicas de músicas compostas por alemães considerados puros, como Richard Wagner, deixando-lhes como opção ouvir a música de Mendelssohn, alemão de origem judaica (o que se pode conferir no documentário Mendelssohn, os Nazistas e Eu, de Sheila Hayman). A ambos os casos é comum a noção de contágio, ideológico num e racial noutro, os nazistas não oferecendo mais que o outro lado da moeda - os judeus contaminariam com sua presença a música da pura raça "ariana", assim como a música burguesa contaminaria seus ouvintes e executores, os quais, para serem descontaminados, libertados dessa cultura, deviam ser reeducados segundo os valores da sociedade camponesa e proletária ${ }^{4}$.

Mais ampla que a purista é a face censória do Politicamente Correto, cujo simplismo, imitando o maniqueísmo da Guerra Fria num contexto pós-Guerra Fria, divide o mundo em bem e mal, certo e errado, ao mesmo tempo em que se pretende acima desses polos ou blocos. O Politicamente Correto não precisa se angustiar com escolhas e deliberações, pois basta-lhe aplicar o código, implementar pretensas e pretensiosas unanimidades: seus discursos não se apoiam na razão para tentar (con) vencer, mas valem-se do poder que detêm ou do qual se consideram portadores, inscrevem-se em gestos e movimentos que vão muito além - ou aquém - da persuasão, chegando quase sempre à intimidação. Não visam a provar ou mostrar que o ponto de vista que expõem é, no final das contas, o correto, ou o mais correto; o que deveria ser seu resultado ou ponto de chegada é seu pressuposto, seu princípio, está

3. A mentalidade que libera - como uma secreção - esse clichê político-ideológico põe a nu a incapacidade (ela sim burguesa, filisteia) de apreciar e fruir obras de arte sem questioná-las ad nauseam: "para que servem?".

4. Numa cena em que a sanha antiburguesa acaba ridicularizada, logo no início do filme de Dai Sijie, os "reeducandos" contornam as pressões quando têm a presença de espírito de reintitular de Mozart está pensando no presidente Mao o minueto do Divertimento $\mathrm{n}^{\circ}{ }_{17}, \mathrm{~K} .334$, que um deles, obrigado pelo chefe da comuna, toca para a plateia aldeã. 
desde o início em sua base. Não pretendem provar nada, não se esforçam em defender nada, pois seu ponto de partida é o pressuposto de que exprimem e manifestam um consenso dado como correto, ou melhor, o correto já dado como consenso. Basta a esses discursos serem apenas a aplicação desse princípio e desse consenso; basta-lhes enquadrar os que infringem o dado e, então, atacá-los, censurá-los, intimidá-los. O poder que detêm e exercem eles o extraem de toda uma ideologia, vivida e exercida como prática cotidiana, que sustenta e permite o (estereó)tipo daquele que se sobrepõe à sociedade no papel de seu guardião, seu salvador.

O guardião do Politicamente Correto é proativo e assertivo no cumprimento de sua cruzada; a certeza do acerto e da legitimidade de sua missão lhe é fornecida pelo caráter de suas ações, precisas e técnicas como intervenções cirúrgicas ou como a proclamação de uma sentença judicial. Nisso consiste a leitura tal como ele a pratica: sonda e esquadrinha o texto à procura do pecado, do crime; ao encontrá-lo, denuncia-o, aplica o diagnóstico, para em seguida ditar a sentença condenatória. Por exemplo, ler Monteiro Lobato significa incriminá-lo automaticamente: "Ele é racista!”. Ou Shakespeare: “É machista!”. Ele não distingue entre autor, narrador e personagens, assim como não diferencia a veiculação de preconceitos da sua representação artístico-literária. O guardião do Politicamente Correto desconhece ironias, ambiguidades, ambivalências, expressões equívocas ou multívocas, precisamente porque seu mundo é simplista, feito de imagens e categorias chapadas, em preto e branco, e assim é que, segundo ele, deve ser imposto, inscrito na realidade: preto no branco...

Esse tipo de leitura, convém lembrar, não deve ser confundido com a crítica ideológica, uma forma de leitura que leva na devida conta as diferenças e as nuances que habitam o texto, na medida mesma em que nele busca as ressonâncias da ideologia de seu tempo e as marcas das ideologias políticas que o permeiam. A leitura ideológica ajuda a compreender a obra, ao explicitar as raízes que ela deita no solo cultural e que explicam, então, sua orientação ideológica. A leitura praticada pelo paladino do Politicamente Correto rejeita in limine essa tentativa de compreensão e explicação. Seu interesse concentra-se em carimbar os autores e suas obras com um selo censório, em termos de pode e não pode.

Sendo "coisa de burguês", o clássico é condenável tanto do ponto de vista da massa quanto de sua vanguarda, o esquadrão do Politicamente Correto (vanguarda, 
aliás, que não deixa de ser uma elites). No entanto - ou melhor, portanto -, o clássico não tem nem deve ter qualquer relevância: ele não passa de mais um entre outros. A cultura do entretenimento de massa é justamente uma imensa planície, sem relevos, e se algum corpo nela sobressai é em função do favor da massa, porque ela o levanta e o põe sobre seus ombros. O clássico só não é completamente nivelado a todos os outros produtos culturais porque dispõe de um privilégio negativo: por ser "coisa da elite", merece ser priorizado na vigilância; por ser trabalhado na escola, a atenção sobre ele, a fim de coibir seus crimes e corrigir seus erros, deve ser redobrada.

O antielitismo é, dessa forma, complementado e reforçado por um demagogismo ao mesmo tempo nivelador e discricionariamente seletivo, que descura ou vê com ampla simpatia todas as iniciativas classificatórias e hierarquizantes promovidas no seio da massa, ao estilo das disputas de times de futebol ou da publicidade da marca de eletrodoméstico, mas reage com antipatia ou ferocidade quando topa, no âmbito da cultura escolar ou acadêmica, com classificações similares. Assim, admite e até incentiva que se diga quem é o maior e/ou o melhor, ou seja, quem é e quem não é "uma brastemp", mas não autoriza que se estabeleça hierarquização semelhante em domínios nos quais emerge a diferenciação entre o artístico e o não artístico, ou entre o elaborado e o tosco. Na medida em que a existência de clássicos se funda na aceitação desse tipo de hierarquização, esse viés demagógico, ao decretar a igualização e o nivelamento de autores e obras, determina a supressão do clássico, inclusive e sobretudo na forma de sua lição: "E daí que Machado de Assis escreve assim ou assado? Quem é ele para servir de modelo ou regra?”.

O resultado, como no caso do aluno comum - aquele que passa pelo processo de escolarização com a função consumidor ligada no piloto automático, sem adquirir a função leitor -, é a subtração: o clássico é submetido a uma conta de menos, subtraído do aprendizado. Com uma diferença: o aluno consumidor desqualifica e exclui o clássico de forma quase passiva, pelo mero motivo de que ele não satisfaz sua ânsia de diversão, não lhe fornece a dose de estímulo que demanda. Trata-se de uma espécie de capricho egoístico; ele não se importa se outro alguém "curte" ou mesmo gosta do clássico. Não acontece o mesmo com o guardião do Politicamente Correto: em sua sanha de tutelar e proteger a massa de más influências, a conta de subtração ele a calcula no papel de inquisidor e juiz, com método e sistema - exclui

5. A ideia de que a massa tenha sua elite não deve estranhar; ela é requerida justamente para entronizar esse novo herói, o paladino do Politicamente Correto. 
o clássico investigando-o, denunciando-o, elaborando a peça de acusação, condenando, prolatando a sentença e aplicando-a.

\section{TERCEIRo CÍRCulo}

Esse mix de antielitismo e demagogismo frequenta o espaço tanto desse segundo círculo quanto de um terceiro, cujos contornos são desenhados por uma prática ideológica que se constitui como expressão ou aplicação dos pressupostos do multiculturalismo, sobretudo os emanados da teoria do relativismo cultural. Partindo do princípio de que há culturas, nenhuma das quais com o direito de sobrepor seus valores às demais, essa prática consiste na recusa - por princípio, retome-se - da possibilidade de existência de uma cultura humana ou humanista de extensão ou validade universal. O clássico acaba então relativizado, neutralizado, anulado: Shakespeare não passa de um dramaturgo inglês da Era Elisabetana... O que justifica que seja lido e estudado numa escola brasileira, no seio de uma cultura com valores, raízes e características que remontam a outras culturas que não a do "bardo inglês"? A resposta é: nada; ler e estudar Shakespeare seria incorrer em “eurocentrismo”... Seria o caso, então, de reivindicar e demandar aulas sobre as literaturas e os pensamentos representativos de culturas ameríndias e africanas? Também não, pois os valores dessas culturas também são relativos, sendo elas, portanto, igualmente passíveis desse questionamento: não sendo universais, o que pode justificar que se privilegie ou escolha seu ensino em sala de aula? Desse modo, o que se empreende em tal caso é uma conta de soma zero: todas as culturas valem, na medida exata em que nenhuma vale mais que a outra, e disso resulta que nenhuma tem o direito de dizer: "ensina-me" e/ou "aprende-me".

A prática ideológica desse relativismo ignora a porta que o universalismo humanista abre para a singularidade do indivíduo, que a pode afirmar na medida mesma em que se declara na posse de um caráter humano e reivindica assim seu lugar no gênero humano, como faz Shylock na conhecida e amiúde citada passagem de $O$ mercador de Veneza, em que tenta justificar seu desejo de vingança:

Sou um judeu. Então, um judeu não possui olhos? Um judeu não possui mãos, órgãos, dimensões, sentidos, afeições, paixões? Não é alimentado pelos mesmos alimentos, ferido com as mesmas armas, sujeito às mesmas doenças, curado pelos mesmos meios, aquecido e esfriado pelo mesmo verão e pelo mesmo inverno que um cristão? Se nos picais, não sangramos? Se nos fazeis cócegas, não rimos? Se nos envenenais, não 
morremos? E se vós nos ultrajais, não nos vingamos? Se somos como vós quanto ao resto, somos semelhantes a vós também nisso. Quando um cristão é ultrajado por um judeu, onde coloca ele a humildade? Na vingança. Quando um judeu é ultrajado por um cristão, de acordo com o exemplo cristão, onde deve ele colocar a paciência? Ora essa, na vingança. (SHAKESPEARE, 1989, II, p. 467).

Shylock é esse outro do cristão: um outro que se afirma tão humano quanto o cristão, mas na medida mesma em que deixa manifesta sua individualidade - pois, se é judeu, não é aí que se dá ou se esgota sua essência ou modo de ser; o que ele é, como judeu, não se distingue essencialmente do que é um cristão; portanto, o que de fato o distingue não se deve à sua pertença à etnia ou cultura judaica, mas ao fato de ser o indivíduo que é ${ }^{6}$.

Num movimento diametralmente inverso, o relativista tende a tomar o outro como integrante e representante de uma cultura e/ou etnia, não como um indivíduo concreto. A singularidade, para ele, se esgota nesse nível coletivo, cultural; ao reconhecê-la, na gesticulação automática provida por essa prática ideológica, ele se dá por satisfeito, orgulhando-se e parabenizando-se por ser tão generoso (e secreta, intimamente: superior) em seu respeito à alteridade. Mas trata-se, retome-se, de um outro subsumido à cultura da qual faz parte (ou na qual é classificado), sendo igualmente forte a tendência - ou o risco - de se enfiá-lo em estereótipos, mesmo que "positivos", justamente na proporção em que não se vai além da apreensão étnico-cultural para se alcançar a dimensão individual.

O relativismo está longe de ser - ou mesmo de poder ser - o antídoto do racismo e das pretensões de superioridade racial, inclusive porque tais pretensões habitam muitas culturas étnicas como traços próprios, que as caracterizam. $\mathrm{O}$ argumento relativista, que propõe que as culturas sejam respeitadas - e/ou se respeitem mutuamente - na medida em que são diferentes entre si, não sensibiliza o racista, não o impedindo nem o dissuadindo de sofismar: ele assume de bom grado a premissa segundo a qual as culturas são diferentes, ao mesmo tempo em que não vê dificuldade alguma em

6. Não há qualquer contradição entre a perspectiva universalista e o reconhecimento do indivíduo como tal, o que se constata em práticas cotidianas, quando, por exemplo, alguém interpela ofensivamente um outro, tomando-o como membro de uma cultura étnica - “Ora, seu judeu!..." - e um terceiro intervém admoestando: "Ei, ele tem nome!..... Esse tipo de chamamento e de advertência recorda e assinala ao mesmo tempo a humanidade e a identidade do ofendido, ou seja, o seu pertencimento ao gênero humano e a sua dignidade de pessoa humana, na condição de indivíduo singular. 
desvencilhar-se da outra premissa (a do respeito), sacando o etnocentrismo dentre as características definidoras da cultura a que pertence - reconhecer a diferença significa, para ele, admitir a superioridade de sua cultura sobre outras.

Na experiência histórica, o argumento que o discriminado levanta contra a discriminação é justamente o do universalismo, o da humanidade tomada como a ideia, $o$ preceito e o parâmetro de um substrato comum: nem judeus nem quaisquer integrantes e representantes de etnias outras são inferiores aos "arianos", pois são todos humanos. Síntese expressiva desse argumento pode ser encontrada na passagem com que Sartre (1970, p. 151) encerra seu relato autobiográfico, As palavras: "Todo um homem, feito de todos os homens, que os vale a todos e a quem vale não importa quem." Tratase, incontrastavelmente, de humanismo e de universalismo: os indivíduos valem - e/ ou devem valer - uns para os outros porque são "simplesmente" humanos, não porque portadores das diferenças e das singularidades das culturas às quais pertencem.

Retomando a temática e o contexto educacionais e fechando o círculo: a noção de singularidade com que se opera na prática ideológica do relativismo cultural e que impera como valor máximo, determinando o respeito ao caráter único de cada cultura, torna impossíveis a comunicação e o diálogo entre elas, ao tratá-las como mônadas, perfeitas unidades fechadas em si mesmas, o que decreta uma espécie de solipsismo cultural, cujo corolário pode verificar-se na impossibilidade de tomar partido: ante conflitos motivados por diferenças e divergências étnico-culturais, a prática relativista lembra o impasse do asno de Buridan, pois o princípio-mestre de que as culturas todas se equivalem entre si (um juízo de valor erigido e praticado como juízo de fato e, no frigir dos ovos, paradoxalmente, como dogma) só pode ditar como norma de conduta a isenção, a neutralidade de quem ou abdica liminarmente de considerar a questão, na ausência de parâmetros de julgamento e comparação, ou reconhece que ambas as partes têm razão.

Inviabiliza-se assim o ensino concebido como formação do humano mediante a cultura humana, concepção que pressupõe ou postula a existência de um universal humano ou do humano como universal, numa aposta ou esperança de promover o diálogo entre as diferentes culturas, em sua acepção antropológica, explorando seu substrato comum - humano - ao mesmo tempo em que observa e transcende suas diferenças. Um projeto desse tipo, no qual, como diz Olivier Reboul (1988, p. 18), "ensinamos Pascal $e$ Voltaire, Goethe $e$ Shakespeare', não como crentes, ou

7. Reboul, como se vê, grifa a partícula e, enfatizando o sentido de adição. 
descrentes, alemães, ou ingleses, mas como universais, isto é, humanos", com o propósito não de "formar um técnico, um cidadão, um crente, mas um homem", proporcionando ao aluno uma iniciação que não se destina "a integrá-lo nesta ou naquela comunidade nacional, profissional ou religiosa, mas para fazê-lo entrar na comunidade humana, transcendente às épocas e às fronteiras" - esse projeto não encontra razão de ser nem possibilidade de existência numa prática relativista que, partindo do princípio de um absoluto respeito à diversidade, à multiplicidade e à singularidade das culturas étnicas, parece ser capaz apenas de acenar para um processo de crescentes fragmentação e afunilamento do interesse como fonte legitimadora dos conteúdos e disciplinas escolares, processo cujo termo, a rigor, é indefinido (em suma: se não interessa estudar culturas nacionais, que se passe para as regionais; se essas também não interessam, que se estudem as grupais, tribais... até se chegar à gangue do bairro, a qual, ainda assim, pode não justificar o estudo, porquanto continua sendo tão só uma cultura entre inúmeras...).

A soma do múltiplo, do diverso, do singular, excluindo a priori e necessariamente (ou logicamente) o universal, redunda, desse modo, em zero ensino: que cultura, com efeito, pode ter a pretensão de ensinar o que é ser humano a outra cultura? No máximo, pode-se cogitar em intercâmbio, o que não é ensino. Esse pressupõe e implica que haja um universal humano, que não existe; portanto...

\section{O vicioso...}

É talvez perceptível que esses círculos são concêntricos, mas não concentracionários, podendo-se dizer que os obstáculos e adversidades são localizados e representariam exemplos isolados. Seria o caso de notar, então, que nada disso afetaria de modo significativo a categoria e a vida dos clássicos - eles continuariam vivos, persistiriam sendo lidos pelos séculos vindouros, como têm sido também há séculos, a despeito dos ataques e negações. Muito certamente: "os cães ladram e a caravana passa..."

Essa capacidade de sobrevivência - ou sobrevida - dos clássicos seria testada e atestada por sua relação paradoxal com a tradição ou as tradições. Os clássicos fazem parte de uma tradição, são por ela carreados e conservados, mas não constituem eles próprios uma tradição, no sentido de determinarem, acerca de si mesmos, interpretações canônicas; o fato de que a herança cultural que representam não só pode como deve ser interpretada em múltiplos sentidos indica que a presença e a persistência dos clássicos sinalizam, como sugere Hannah Arendt (1972, p. 28), o fim da tradição, 
a ausência de um solo (um mundo) comum que assegure uma direção igualmente comum ou consensual para as interpretações. Pode-se, portanto, contestar e tentar destruir um clássico - sua reputação, seu status - mas isso num ambiente em que o clássico já não diz sempre a mesma coisa; ele é múltiplo, proteiforme, dado a inúmeras visões e leituras. O que o mantém vivo é, então, essa polissemia, essa riqueza de significações, a abertura a um sem número de abordagens, que dele faz uma referência (viva, justamente) mas não um referencial no sentido acadêmico do termo: a leitura dos clássicos, nesse sentido, proporciona inestimáveis fundamentos e parâmetros para a formação do gosto e para a apreciação em profundidade da cena e do panorama culturais, que podem ser então tomados em perspectiva, segundo escalas de valores hauridas na própria cultura e em suas tradições; mas quando, violentando-se e reduzindo-se essa relação, procura-se usar e adotar um clássico como instrumental de pesquisa, acaba-se na situação aberrante de especialistas que sabem operar e aplicar os conceitos, mas ignoram toda a atmosfera cultural respirada pelo clássico e que dele emana. No caso específico dos clássicos da Antropologia, seria necessário acrescentar, no entanto, que essa vida se manifesta talvez até ao limite da autodestruição, se se perceber naquela prática derivada da teoria multiculturalista um movimento pelo qual uma cultura de extração europeia, na medida em que se dispõe a abrir-se às outras culturas, relativiza-se ao ponto de negar e destruir a tradição em que se enraíza.

Cabe reconhecer, portanto, que clássicos continuam existindo e que, mais que isso, mantêm sua influência: é justamente porque tomam e estudam como clássicos os teóricos do relativismo cultural que universitários se põem a defender, como ideólogos, os postulados e derivados da teoria, mas o fazem quase que desapercebidamente, pois acusam e atacam posturas e pontos de vista "eurocêntricos", onde quer que os encontrem, sem se darem conta de que a atitude que fundamenta tais acusações e ataques radica em solo cultural europeu, tendo sido cultivada no século XVI por um Montaigne e no XVIII por um Voltaire - autores nos quais se pode verificar que a postura ou inclinação relativística não é menos construída culturalmente que a universalista, ambas compartilhando, no final das contas, o mesmo chão ideológico, de extração europeia.

Mas mesmo essa presença quase imperceptível - ao mesmo tempo em que conscientemente recusada - do clássico pressupõe o que apontamos no início, ou seja, que ele e sua importância não são autoevidentes; pelo contrário, dependem de que haja leitores - mais especificamente, leitores de clássicos, que os reconheçam e cultivem como tais. Sua sobrevivência - ou sobrevida - implica a formação de leitores, que 
crianças e jovens não se restrinjam à função consumidor, mas, para além dela, adquiram e assumam a função leitor... A tradição da leitura e dessa formação apontava justamente o clássico como forma, meio e modelo para a aquisição dessa função: aprendia-se a ler lendo os clássicos, o que implicava - como ainda implica - trabalho, ou seja, estudo ${ }^{8}$.

Num mundo que tende, aparentemente com crescente intensidade, a relativizar, a neutralizar, a anular o clássico, a submetê-lo a inquéritos policialescos, a julgamentos e a execuções sumárias, é de fato imprescindível assinalar a importância de ler os clássicos. Mas aí se tromba com o pior círculo - o vicioso -, isto é, com uma espécie de petição de princípio, pois o objetivo que se quer realizar e as condições que possibilitam sua realização coincidem no mesmo ponto, remetem à mesma carência, ao mesmo vazio: para provar a importância de ler os clássicos é necessário que se reconheça a existência de clássicos, ao mesmo tempo em que, para obter tal reconhecimento, é necessário que se leiam os clássicos...

Ainda ecoam os versos, portanto:

Meu caro Luís, que vens fazer nesta hora

de antimúsica pelo mundo afora?

\section{REFERÊNCIAS}

ANDRADE, Carlos Drummond de. Beethoven. In: . As impurezas do branco. 4. ed. Rio de Janeiro: José Olympio, 1978.

ARENDT, Hannah. Prefácio: A quebra entre passado e futuro. In: . Entre o passado e o futuro. Trad. Mauro W. Barbosa de Almeida. São Paulo: Perspectiva, I972. p. 28-42.

8. A tentação, dado o ambiente que vimos descrevendo, é a de substituir o valor ("ler os clássicos é melhor do que não lê-los") pelo efeito, em termos como: "Os professores de Literatura em geral dizem que é preciso ler porque é importante. Acho que eles não gostam de ler. É preciso ler porque é divertido, [...] porque é gostoso, porque você dá muita risada com Macunaíma" (Frederico Barbosa, no filme Mestres da Literatura - Mário de Andrade: reinventando o Brasil, 29min21s e 29min46s). Cabe observar que divertir-se com Macunaíma é algo assaz diverso do entretenimento a que as massas estão acostumadas e condicionadas: supõe uma preparação, um trabalho pelo qual se aprende a ver a graça (e outros encantos) desse e de outros livros, havendo uma considerável diferença a separar e a distanciar o "aprender a divertir-se", em tal caso, do "aprender divertindo-se" proposto e defendido por pedagogos que se precipitam em funcionar como Ersatz dos ídolos midiáticos. Curiosamente, é de um profissional da mídia que vem uma opinião mais pertinente e lúcida: falando sobre Ulysses, de James Joyce, durante uma de suas aparições no programa Manhattan Connection, em 7 de setembro de 2014, Diogo Mainardi assinala e enfatiza que a leitura e a fruição desse clássico moderno exigem e pressupõem - fundamentalmente - o estudo. 
BALZAC e a costureirinha chinesa. Direção: Dai Sijie. Produção: Les Films de la Suane, TFI Films Productions. Intérpretes: Xun Zhou, Kun Chen, Ye Liu, Shuangbao Wang, Zhijun Cong, Hong Wei Wang, Xiong Xiao, Zuohui Tang, Wei Chen, Tianlu Chen, Qing-yun Fan. Roteiro: Dai Sijie e Nadine Perront. Título original: Balzac et la petite tailleuse chinoise. Duração: III min. Ano de produção: 2002.

CALVINO, Ítalo. Por que ler os clássicos. Trad. Nilson Moulin. São Paulo: Ed. Schwarcz, 2009. KANT, Immanuel. Resposta à pergunta: Que é "Esclarecimento"? In: Textos seletos. 3. ed. Trad. Floriano de Sousa Fernandes. Petrópolis, RJ: Vozes, 2005. p. 63-7I.

MENDELSSOHN, OS NAZISTAS E EU. Direção e roteiro: Sheila Hayman. Produção: BBC. Gênero: documentário. Título original: Mendelssohn, the Nazis and Me. Duração: 60 min. Ano de produção: 2009.

MESTRES DA LITERATURA - Mário de Andrade: reinventando o Brasil. Disponível em: <http:// tvescola.mec.gov.br/tve/video;jsessionid=B $53742549921 \mathrm{C}_{2} \mathrm{FD}_{57} \mathrm{~F}_{446 \mathrm{EA}}{ }_{23} \mathrm{C}_{5183}$ ?idItem=795>. MONTAIGNE, Michel de. Ensaios. Trad. Sérgio Milliet. São Paulo: Abril Cultural, I972. (Col. Os Pensadores, v. XI).

REBOUL, Olivier. Filosofia da Educação. 7. ed. Trad. Luiz Damasco Penna e J. B. Damasco Penna. São Paulo: Companhia Editora Nacional, 1988.

SARTRE, Jean-Paul. As palavras. 4. ed. Trad. J. Guinsburg. São Paulo: Difusão Europeia do Livro, 1970.

SHAKESPEARE, William. O mercador de Veneza. Trad. F. Carlos de Almeida Cunha Medeiros e Oscar Mendes. In: . Obra completa.v. II. Rio de Janeiro: Nova Aguilar, I989. p. 437-497.

VOLTAIRE [François-Marie Arouet]. Tratado de Metafísica. Trad. Marilena de Souza Chaui Berlinck. São Paulo: Abril Cultural, I972.(Col. Os Pensadores, v. XXIII, com textos de Voltaire e Diderot).

\section{SOBRE O AUTOR}

Roberto Goto é graduado e licenciado em Filosofia (Pontifícia Universidade Católica de Campinas), com Mestrado e Doutorado em Teoria e História Literária (Universidade Estadual de Campinas). Doutorou-se também em Educação (Universidade Estadual de Campinas). Atualmente é professor da Universidade Estadual de Campinas, dedicando-se principalmente aos seguintes temas, áreas e suas inter-relações: educação, filosofia, antropologia filosófica, literatura.

E-mail: goto@unicamp.br

Recebido em 16 de dezembro de 2015 e aprovado em 27 de março de 2016. 